\title{
Effects of Inlet Distortion on Aeromechanical Stability of a Forward-Swept High-Speed Fan
}

Gregory P. Herrick

Glenn Research Center, Cleveland, Ohio 


\section{NASA STI Program . . . in Profile}

Since its founding, NASA has been dedicated to the advancement of aeronautics and space science. The NASA Scientific and Technical Information (STI) program plays a key part in helping NASA maintain this important role.

The NASA STI Program operates under the auspices of the Agency Chief Information Officer. It collects, organizes, provides for archiving, and disseminates NASA's STI. The NASA STI program provides access to the NASA Aeronautics and Space Database and its public interface, the NASA Technical Reports Server, thus providing one of the largest collections of aeronautical and space science STI in the world. Results are published in both non-NASA channels and by NASA in the NASA STI Report Series, which includes the following report types:

- TECHNICAL PUBLICATION. Reports of completed research or a major significant phase of research that present the results of NASA programs and include extensive data or theoretical analysis. Includes compilations of significant scientific and technical data and information deemed to be of continuing reference value. NASA counterpart of peer-reviewed formal professional papers but has less stringent limitations on manuscript length and extent of graphic presentations.

- TECHNICAL MEMORANDUM. Scientific and technical findings that are preliminary or of specialized interest, e.g., quick release reports, working papers, and bibliographies that contain minimal annotation. Does not contain extensive analysis.

- CONTRACTOR REPORT. Scientific and technical findings by NASA-sponsored contractors and grantees.
- CONFERENCE PUBLICATION. Collected papers from scientific and technical conferences, symposia, seminars, or other meetings sponsored or cosponsored by NASA.

- SPECIAL PUBLICATION. Scientific, technical, or historical information from NASA programs, projects, and missions, often concerned with subjects having substantial public interest.

- TECHNICAL TRANSLATION. Englishlanguage translations of foreign scientific and technical material pertinent to NASA's mission.

Specialized services also include creating custom thesauri, building customized databases, organizing and publishing research results.

For more information about the NASA STI program, see the following:

- Access the NASA STI program home page at http://www.sti.nasa.gov

- E-mail your question via the Internet to help@ sti.nasa.gov

- Fax your question to the NASA STI Help Desk at $443-757-5803$

- Telephone the NASA STI Help Desk at 443-757-5802

- Write to: NASA Center for AeroSpace Information (CASI) 7115 Standard Drive Hanover, MD 21076-1320 


\title{
Effects of Inlet Distortion on Aeromechanical Stability of a Forward-Swept High-Speed Fan
}

\author{
Gregory P. Herrick
}

Glenn Research Center, Cleveland, Ohio

Prepared for the

46th Joint Propulsion Conference and Exhibit

cosponsored by the AIAA, ASME, SAE, and ASEE

Nashville, Tennessee, July 25-28, 2010

National Aeronautics and

Space Administration

Glenn Research Center

Cleveland, Ohio 44135 


\section{Acknowledgments}

The author gratefully acknowledges the funding support of the Turbomachinery portion of the Subsonic Fixed Wing Program. Nateri Madavan is the project manager, and Ruben DelRosario is the Program Associate Principal Investigator.

This work was sponsored by the Fundamental Aeronautics Program at the NASA Glenn Research Center.

Level of Review: This material has been technically reviewed by technical management.

Available from

NASA Center for Aerospace Information 7115 Standard Drive

Hanover, MD 21076-1320
National Technical Information Service 5301 Shawnee Road Alexandria, VA 22312

Available electronically at http://gltrs.grc.nasa.gov 


\title{
Effects of Inlet Distortion on Aeromechanical Stability of a Forward-Swept High-Speed Fan
}

\author{
Gregory P. Herrick \\ National Aeronautics and Space Administration \\ Glenn Research Center \\ Cleveland, Ohio 44135
}

\begin{abstract}
Concerns regarding noise, propulsive efficiency, and fuel burn are inspiring aircraft designs wherein the propulsive turbomachines are partially (or fully) embedded within the airframe; such designs present serious concerns with regard to aerodynamic and aeromechanic performance of the compression system in response to inlet distortion. Separately, a forward-swept high-speed fan was developed to address noise concerns of modern podded turbofans; however this fan encounters aeroelastic instability (flutter) as it approaches stall. A three-dimensional, unsteady, Navier-Stokes computational fluid dynamics code is applied to analyze and corroborate fan performance with clean inlet flow. This code, already validated in its application to assess aerodynamic damping of vibrating blades at various flow conditions, is modified and then applied in a computational study to preliminarily assess the effects of inlet distortion on aeroelastic stability of the fan. Computational engineering application and implementation issues are discussed, followed by an investigation into the aeroelastic behavior of the fan with clean and distorted inlets.
\end{abstract}

\section{Nomenclature}

$\begin{array}{ll}\text { BLI } & \text { Boundary-Layer-Ingesting } \\ \text { ECMF } & \text { Exit Corrected Mass Flow (i.e., "exit throttle") boundary condition } \\ \text { ND } & \text { Nodal Diameter } \\ \text { \#NDB } & \text { (\#) Nodal Diameter, Backward-traveling wave } \\ \text { \#NDF } & \text { (\#) Nodal Diameter, Forward-traveling wave } \\ \text { NS } & \text { Near-Stall } \\ \text { PE } & \text { Peak-Efficiency } \\ \text { PRE } & \text { Exit Static Pressure with Radial Equilibrium boundary condition } \\ \text { SPP } & \text { Exit Static Pressure Profile boundary condition. }\end{array}$

\section{Introduction}

Since the advent of turbo/jet propulsion, "clean" intake flow for the fan (or first stage) of the turbomachine propulsor has been the desired, elusive, goal of airframe, inlet, and propulsion system designers alike. Engines mounted at the aft extent of the fuselage ingest flow influenced by the airframe boundary layer. Engines mounted within the tail/aft-fuselage assembly ingest airframe boundary layer and then suffer additional flow degradation due to the serpentine inlet duct. Tail- and aft-fuselage-mounted engines were particularly common in 1960s commercial aircraft design, when propulsive efficiency, noise, and emissions were of lower precedence than today. While modern small subsonic transport designs employ podded engines mounted on the aft-fuselage, these designs do not incorporate engines embedded within the tail assembly. Nearly all large subsonic transport designs since the 1980s have employed podded engines, mounted by pylon, on the wings. With this placement, the engines receive cleaner inlet flow than the aforementioned fuselage-mounted engines, facilitating more powerful, more cost-efficient engine designs than their predecessors. 
As we look to the future, design goals now focus on reduced emissions, reduced fuel consumption, better propulsive efficiency, and reduced ambient noise. Among the prominent design concepts under development for application to future aircraft is the "hybrid wing/body." Most of these prospective designs feature propulsion systems wherein the propulsive fan, whether coupled directly to a Brayton cycle turbine engine or part of a turbo-electric distributed propulsion system, is embedded partially or fully submerged within the body.

The design process has been revolutionized through the aforementioned evolution of airframe, inlet, and propulsion system design. Analytical theory (often with simplifying assumptions) and repeating (costly) cycles of design, build, test have been supplemented greatly with advances in computational technology, both hardware and software. In this research effort, a parallel computational fluid dynamics (CFD) code is modified and customized to begin studying the issues relevant to aeromechanical response of turbomachinery to distorted inlet flows.

\section{Background}

A primary design concept of research interest in the United States is the hybrid wing/body. As its name implies, this design is a departure from the tube-and-wing designs which have populated the skies for the last 60 years. Liebeck (Ref. 1) published an authoritative paper on this airframe concept in 2002. This design melds the wing and body in an integral unit. Among the goals mentioned previously, greater propulsive efficiency is attained with this design by utilizing boundary layer ingestion (BLI). Studies have shown that wake-ingestion can increase propulsive efficiency by 20 percent (Smith (Ref. 2) and Plas et al. (Ref. 3)). While BLI improves propulsion system efficiency, it can wreak havoc on turbomachinery aerodynamics and aeromechanics, and hence high cycle fatigue (HCF), when unchecked. Kenyon et al. (Ref. 4) described the significant role of total pressure flow distortion in the onset of non-uniform flowrelated HCF.

Computational research into inlet distortion concerns ramped up in the mid-1990s. Hah et al. (Ref. 5) were pioneers in numerical analysis of inlet distortion, studying a $1 / 8^{\text {th }}$ sector of a rotor with a total pressure distortion at the inlet plane. They prescribed constant static pressure at one location on the shroud at the exit rotor plane. Hirai et al. (Ref. 6) used full-annulus numerical simulations of a rotor subject to circumferentially non-uniform total pressure at the inlet boundary to investigate the mechanism of pressure loss associated with passage shock motion; they held their exit static pressure constant. Charalambous et al. (Ref. 7) used CFD to study the changes in axial compressor performance due to circumferential and stratified distortions in inlet total pressure; they maintained a constant static pressure at the exit. Yao et al. (Ref. 8) and Gorell et al. (Ref. 9) used CFD to demonstrate that a 1/rev total pressure distortion at the inlet incites a static pressure distortion which in turn induces a swirl distortion; they enforced an interpolated, non-uniform pressure distribution about the exit plane. Bréard et al. (Ref. 10) computed forced response of a fan rotor subjected to inlet distortion; they specified mass flows at blade row interfaces. Zemp et al. (Ref. 11) conducted full-annulus, unsteady CFD simulations of a centrifugal compressor subject to inlet distortion; they applied a uniform average static pressure over the entire exit area which was iteratively adjusted to match computed mass flows with measured mass flows at the respective operating point.

\section{Analysis Code}

The relevant CFD code modified and applied in this study is TURBO. TURBO is a physics-based simulation tool for multistage turbomachinery. The solver computes the fluid conservation laws without ad hoc modeling of any flow phenomena other than models required for turbulence. This code solves the unsteady Reynolds-averaged Navier-Stokes equations and a decoupled k- $\varepsilon$ turbulence model developed by Zhu and Shih (Ref. 12). To facilitate rotor-stator interaction, TURBO employs a sliding interface technique implemented by Chen and Barter (Ref. 13) in which conservative variables are interpolated 
across blade row interfaces. The code is implemented in a portable, scalable form for distributed-memory parallel computers using MPI message passing. The parallel implementation employs domain decomposition and supports general multi-block grids with arbitrary grid-block connectivity. The solution algorithm is a Newton iterative implicit time-accurate scheme with characteristics-based finite-volume spatial discretization. The Newton subiterations are solved using a concurrent block-Jacobi symmetric Gauss-Seidel (BJ-SGS) relaxation scheme. Because all of the fundamental fluid mechanics are computed, the code is capable of capturing the nonlinear characteristics of the flow fields of interest. With the actual modeling of the grid movement of the blade rows in relative motion, this code is capable of computing the unsteady interactions between blade rows. Details of the flow solver are given by Chen and Whitfield (Ref. 14). The approach to parallelization for large-scale, complex problems is discussed by Chen and Briley (Ref. 15). TURBO has been previously modified for application to study flutter and forced vibration (Refs. 16 to 18). TURBO has been further validated in several previous research efforts regarding aeromechanics (Refs. 19 to 24 ).

\section{Computational Research Test Article}

A high-speed, forward swept fan has been developed for research purposes. Its raison d'être was the study of new design concepts with respect to noise and acoustics. In the course of development and testing, aeromechanical concerns arose. The fan was aeroelastically stable in most operating conditions, but flutter was observed during physical testing at low-flow conditions above the operating line. Concomitant and complementary CFD analysis using TURBO proved to accurately simulate the aeroelastic stability (and instability) of the fan for the mode of concern along the speedline of concern. Given the corroboration and mutual validation of physical experiment with this fan and TURBO simulations of this fan, this fan is ripe for studying aeroelastic response to inlet distortion. Will previously stable points become unstable? Will already-unstable points become more unstable? Will previouslyunstable points become stable? Also of interest, how will fan aerothermodynamic performance be impacted?

\section{Physical and Computational Definition of Fan}

The fan of interest is comprised of twenty-two blades. The fan was designed for purposes of noise reduction in a typical podded-engine mounting. The fan was never intended to be part of an embedded propulsion system with distorted inlet flow, but it is studied in this vein because of corroboration between the computational and experimental results with regard to flutter assessment (with clean inlet flow). Computationally, the fan is preceded by inlet duct of length-ratio 1.373 with respect to blade axial chord and followed by exit duct of length-ratio 2.364 with respect to blade axial chord. Physically, the average radial tip gap at the rotational speed of interest is about 98.4 percent of blade radial span; in the initial study, four computational volumes filled this tip gap. A CFD H-mesh representation of the fan is pictured in Figure 1; this refined mesh was constructed in the course of this study.

\section{Initial Simulation and Validation}

In the initial application of TURBO for the aeroelastic study of this fan, single-passage simulations with appropriate periodic or phase-lag boundary conditions were employed. With the desire to study inlet distortion typical to serpentine ducts and embedded inlets, single-passage and even multi-passage periodic-sector models are not adequate. Full-annulus simulations must be performed, at the (large) added expense of computational resource requirements. In-house codes used to pre-process TURBO inputs and post-process TURBO outputs have been developed and modified to facilitate full-annulus TURBO simulations for both aerodynamic and aeroelastic studies. Figures follow which demonstrate the consistency of solution from serial TURBO single-passage solution to parallel TURBO full-annulus solution of the original grid. Each of these charts arises from clean inlet (axisymmetric radial distortion) 
flows. The general aeroelastic response of the fan has been retained as shown in Figure 2, while slight circumferential blade-to-blade variations become more pronounced in higher nodal-diameter modes of the full annulus configuration in Figure 3. Such circumferential variation in response to clean inlet flow further incites the study which follows.

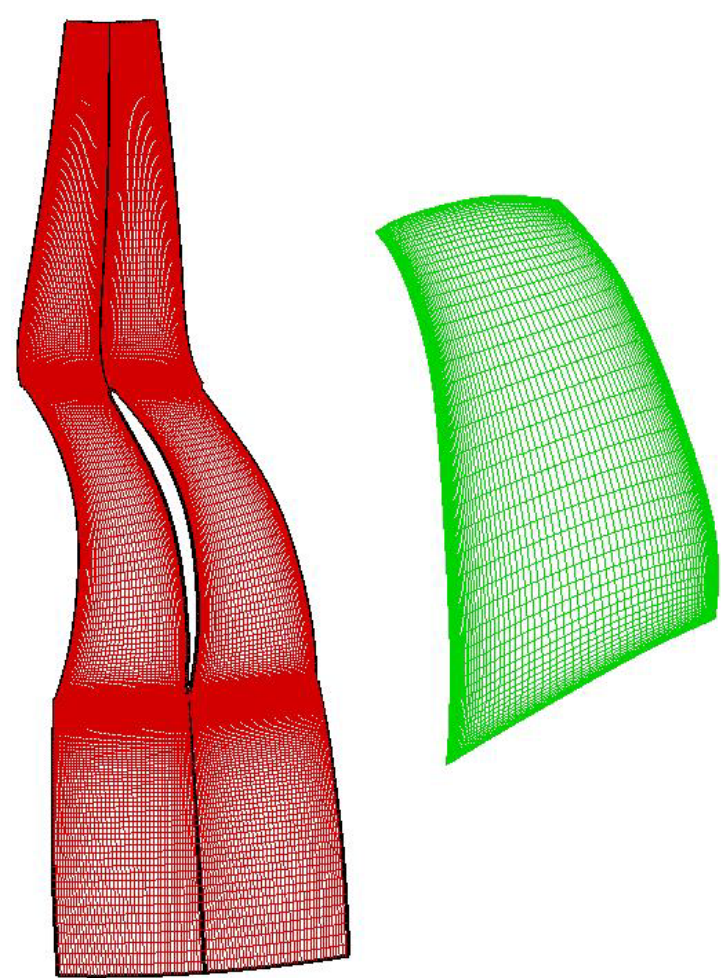

Figure 1.-(Refined) H-Mesh of research fan.

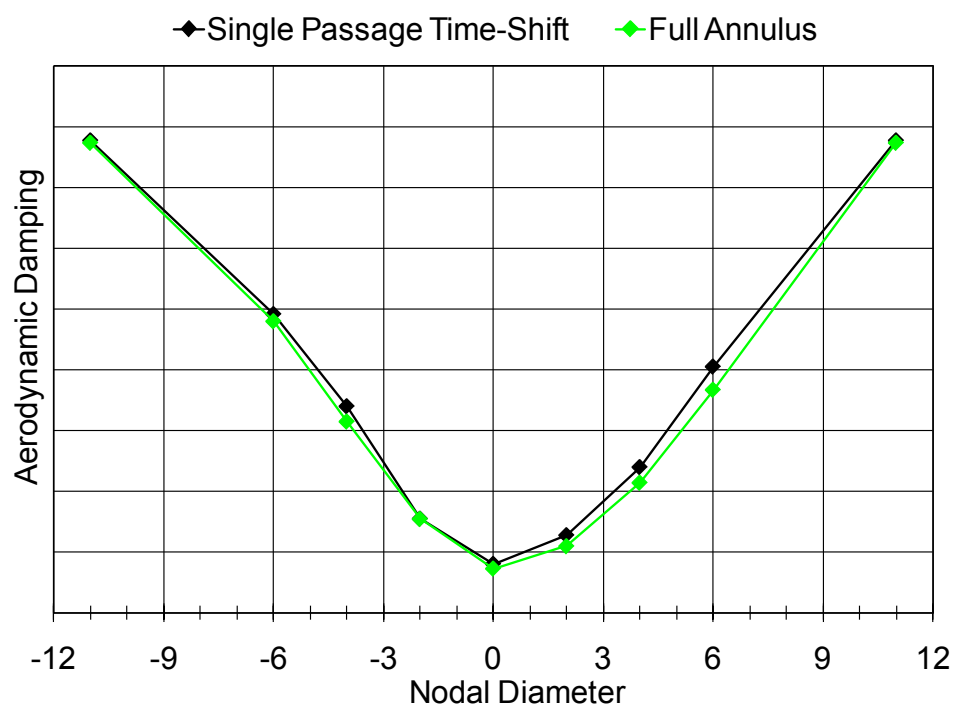

Figure 2.-Consistent results through code evolution and solution refinement. (Peak efficiency, original grid, static pressure profile exit) 


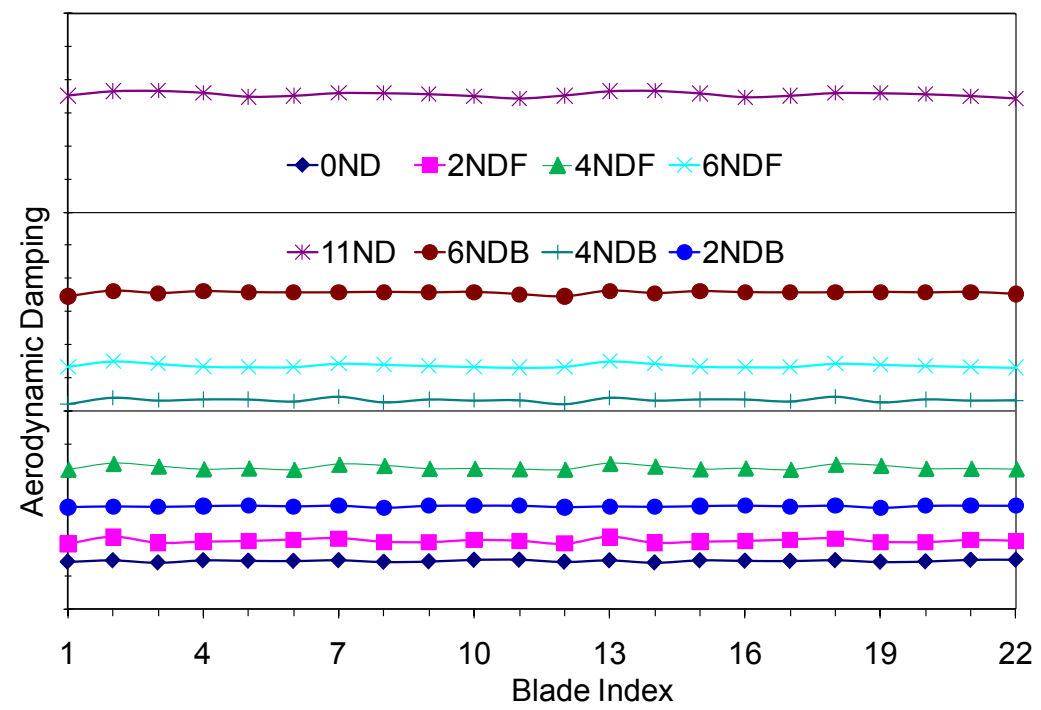

Figure 3.- Slight blade-to-blade variation observed in full-annulus simulations. (Peak efficiency, original grid, static pressure profile exit.)

\section{Computational Considerations}

\section{Refining the Grid}

The original grid proved exceptional in computational efficiency for solution of single-passage configurations (periodic and time-shift alike) with constant static pressure profile ("SPP") exit boundary conditions. However, the nature of inlet distortion suggests that a throttle exit boundary condition, which would not prescribe nor enforce two-dimensional spatial distribution of any aerothermodynamic quantities within the exit plane, facilitates better solution to such flow conditions than a constant static pressure profile exit boundary condition. A throttle exit boundary condition is thus applied to this original grid. Figure 4 shows the excellent overlap between simulations with constant static pressure profile exits and simulations with throttle exits ("ECMF": Exit Corrected Mass Flow) from choke through peakefficiency and slightly beyond. Approaching stall, however, the throttle does not adequately converge to a single, quotable result for this original grid. Previous computational research using TURBO on nonaxisymmetric flows documents TURBO's success in simulating nonaxisymmetric and/or unstable flows with the throttle boundary condition (Ref. 25). Attributing the failure of the throttle boundary condition with this original grid to mesh density, the author refines the grid with 25 percent more volumes spanwise in the tip gap, 20 percent more volumes spanwise on the blade, 41 percent more volumes streamwise on the blade, 180 percent additional streamwise volumes in the inlet, and 156 percent additional streamwise volumes in the exit grid. The significant refinement in the streamwise direction was deemed critical in preserving the non-axisymmetric character of the flow through its streamwise progress. The refined grid also contains 16 percent additional volumes circumferentially. The demand for computational resources directly proportional to total volume count - was a practical consideration throughout the refinement process. 


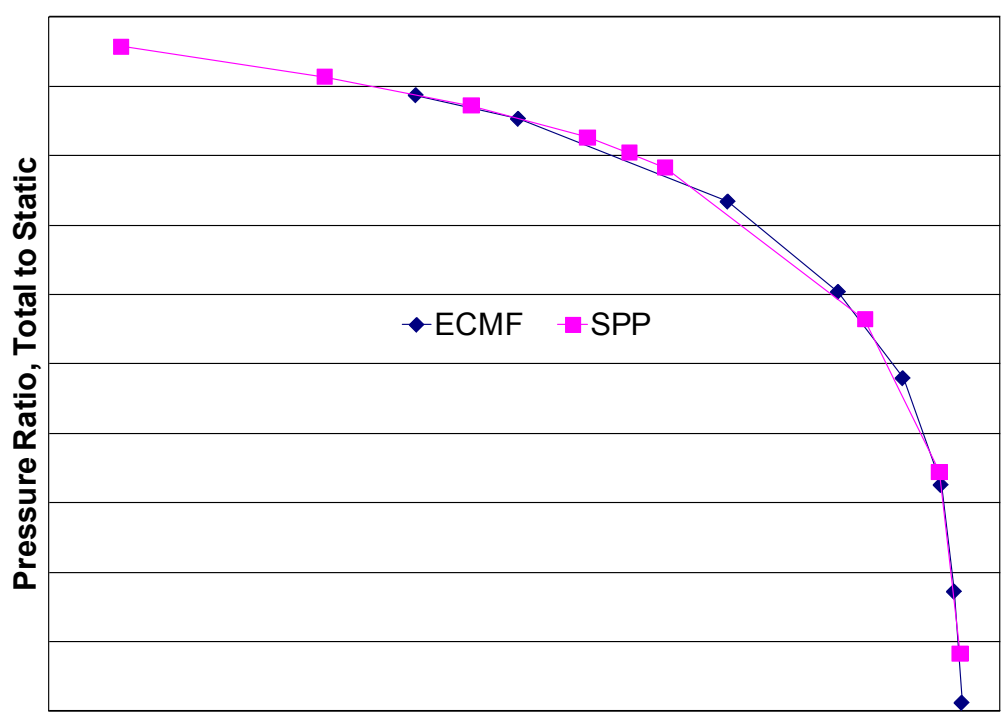

Physical Mass Flow

Figure 4.-Throttle exit boundary condition does not converge with full flow range of constant static pressure profile exit boundary condition on original grid.

\section{Inlet Distortion Boundary Condition}

The crux of this study lies in accurately capturing and maintaining a prescribed inlet distortion boundary condition. TURBO has long supported an isentropic inlet boundary condition (Ref. 14) wherein total conditions (with variation allowed only in the radial direction) are held as dictated by the characteristics. This boundary condition is very well suited for stable flows which exhibit variation between hub and casing (axisymmetrically) only, but this boundary condition must be modified to allow for circumferential variation when studying inlet distortion flows. For this study, the inlet boundary condition is modified to allow for user-specified prescription of total temperature, total pressure, radial flow angle, and tangential ("swirl") flow angle about a user-specified orthogonal polar grid. To enforce the prescribed circumferentially-varying flow conditions before a rotor, the distortion pattern must be interpolated, at each time step, upon backward-rotating rotor grids. (N.B.: TURBO computes the passage flows using stationary grids and applies appropriate body forces.)

Of particular interest to NASA in the development of propulsion systems for the hybrid wing/body aircraft concept is the BLI inlet concept, studied by Berrier et al. (Ref. 26) at Langley Research Center, known as "Inlet A". This inlet's total pressure $\left(\mathrm{P}_{\mathrm{T}}\right)$ distortion pattern, approximated as planar-symmetric, is shown in Figure 5. For comparison purposes, the clean inlet distribution of inlet total pressure for which this fan was designed is shown in Figure 6. The Inlet A pattern features a 10.5 percent spread in $\mathrm{P}_{\mathrm{T}}$, while the lowest $\mathrm{P}_{\mathrm{T}}$ in the clean inlet is 12 percent less than the clean inlet maximum $\mathrm{P}_{\mathrm{T}}$. The areaaveraged total pressure of the distorted inlet is about 4 percent less than the area-averaged total pressure of the clean inlet. No circumferential distortion in total temperature, radial flow angle, or swirl is incorporated in the present study due to lack of data. 


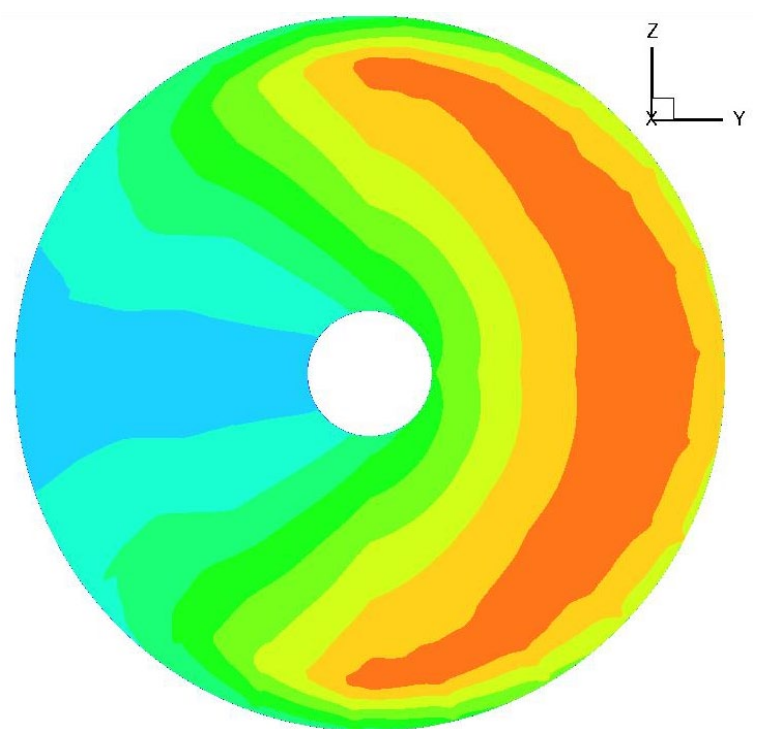

Figure 5.-Approximation of Inlet A distortion pattern (total pressure; red is high).

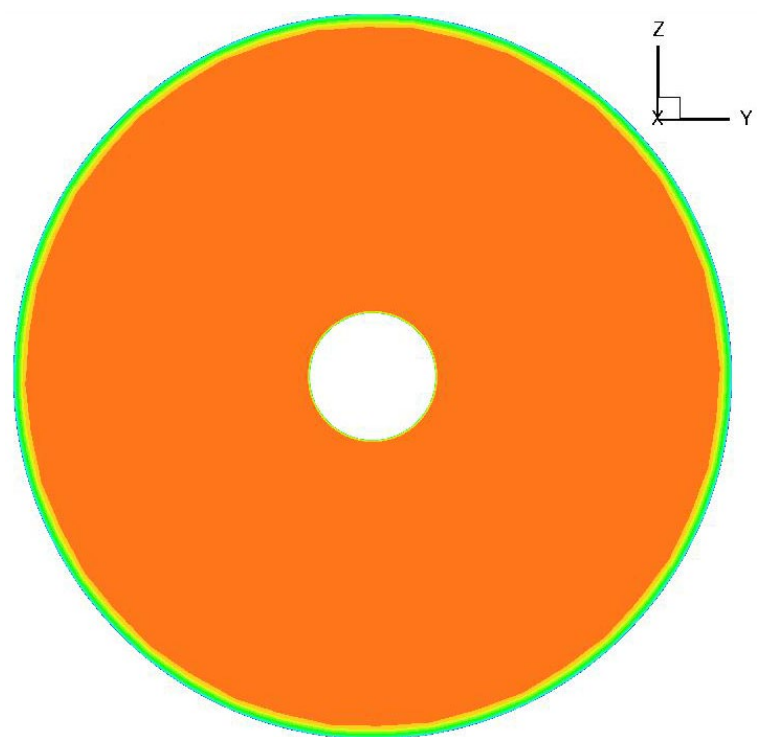

Figure 6.-Design clean inlet total pressure distribution (red is high).

\section{Validating the Throttle Exit Boundary Condition for This Study}

Having refined the grid to enhance the accuracy and applicability of the throttle exit boundary condition for nonaxisymmetric flow simulations such as these, the behavior of this exit boundary condition on the refined grid must be verified. In Figure 7, the behaviors of exit constant static pressure profile, exit constant static pressure with radial equilibrium ("PRE") held at hub, and exit corrected mass flow boundary conditions are plotted. As shown in Figure 7, with appropriate refinement, the exit corrected mass flow boundary condition emulates the aerothermodynamic performance of the exit constant static pressure profile and exit constant static pressure with radial equilibrium held at the hub, while this throttle boundary condition also demonstrates (more accurate) increased range from choke to stall.

Given the impetus to employ this boundary condition, it is further instructive to inspect the resulting exit pressure field when unconstrained with regard to spatial distribution. Figure 8 depicts the (expectedly) very axisymmetric distribution of exit static pressure from a full annulus simulation of the refined grid with the throttle exit boundary condition and a clean inlet (cf Figure 6). Next in Figure 9, the exit static pressure field from a full annulus simulation of the refined grid with the throttle exit boundary condition and the distorted inlet (cf Fig. 5) is shown. Clearly, non-axisymmetric and planar asymmetric flow conditions remain at the exit plane, and thus an exit boundary condition specifying uniformity, axisymmetry, circumferential periodicity, or planar symmetry would be (inaccurately) over-constraining the exit flow field. Thus the corrected mass flow "throttle" exit boundary condition is deemed most appropriate for further study of "Inlet A" inlet distortion flows. 


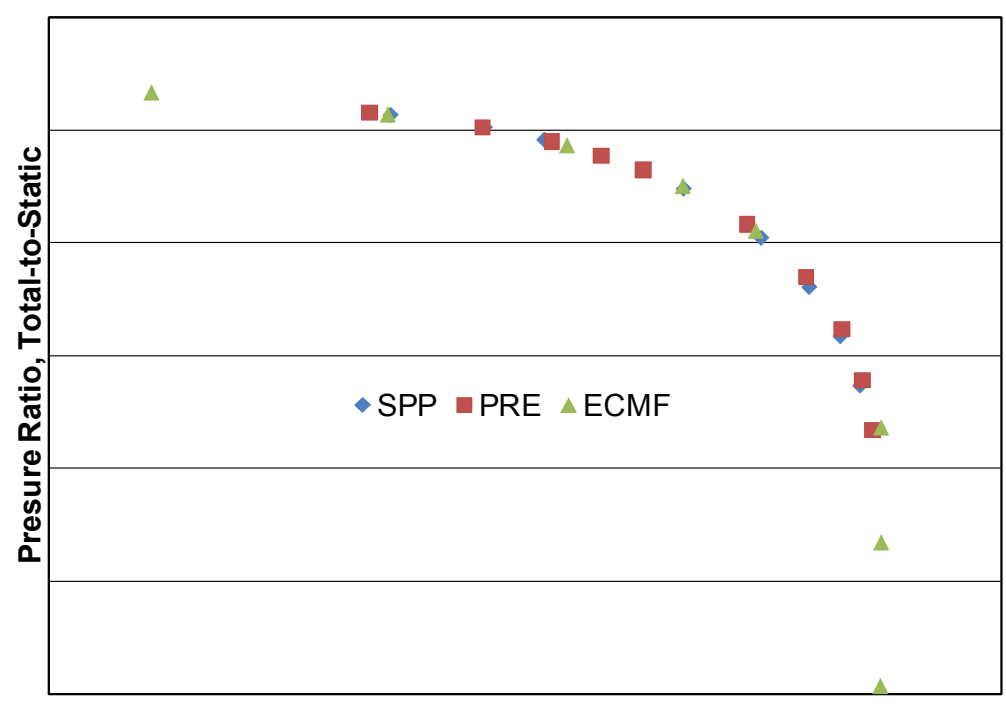

Physical Mass Flow

Figure 7.-Throttle exit boundary condition exhibits greater flow range than static pressure profile and static pressure/radial equilibrium boundary conditions on refined grid.

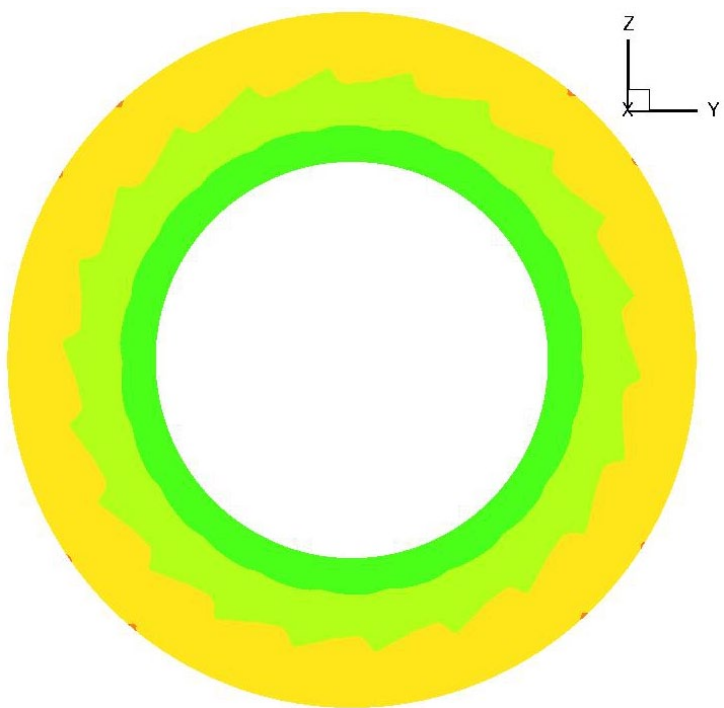

Figure 8.-Exit static pressure distribution from clean inlet simulation (Red is high).

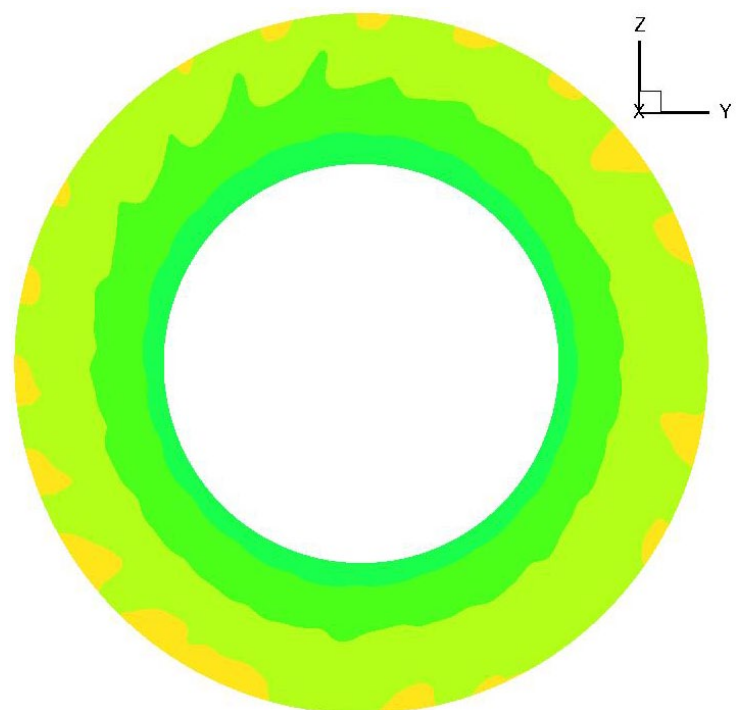

Figure 9.-Exit static pressure distribution from distorted inlet simulation (Red is high).

\section{Clean Inlet v Distorted Inlet: Aerothermodynamic Performance}

As is readily understood and previously demonstrated here, the "local" aerodynamic behavior of the fan is greatly impacted by the condition of the inlet flow. The global aerothermodynamic performance is also impacted by inlet distortion: Figure 10 demonstrates the decreased physical flow at choke for the distorted inlet scenario: the 4 percent decrement in physical mass flow choke is directly commensurate with the 4 percent decrement in area-averaged inlet total pressure. Of greater interest, however, is the overall performance as gauged by pressure ratio versus corrected flow; see Figure 11. Observe that when viewed from the corrected basis, the pressure recovery is nearly unchanged between the clean inlet and the distorted (weakened) inlet. The pumping behavior of the compression system is almost independent of inlet flow condition, whether it be a "global", "absolute" change in inlet pressure (e.g., flight altitude) or the "local", "relative" change in inlet pressure inherent to inlet distortion. 


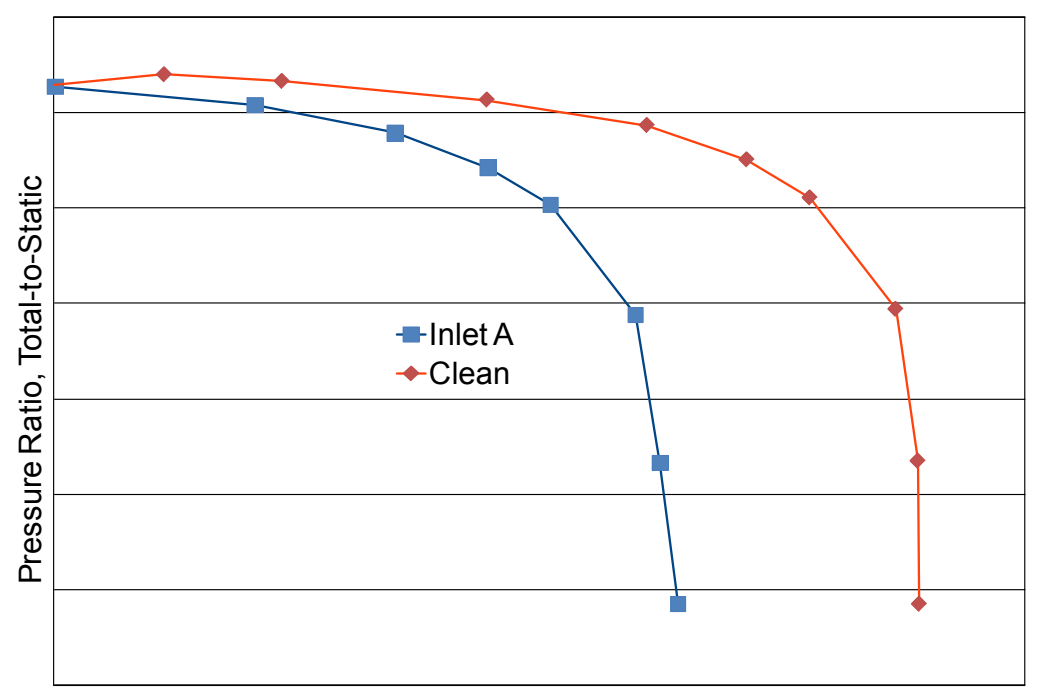

Physical Mass Flow

Figure 10.--Pressure ratio v physical mass flow for clean and distorted inlets.

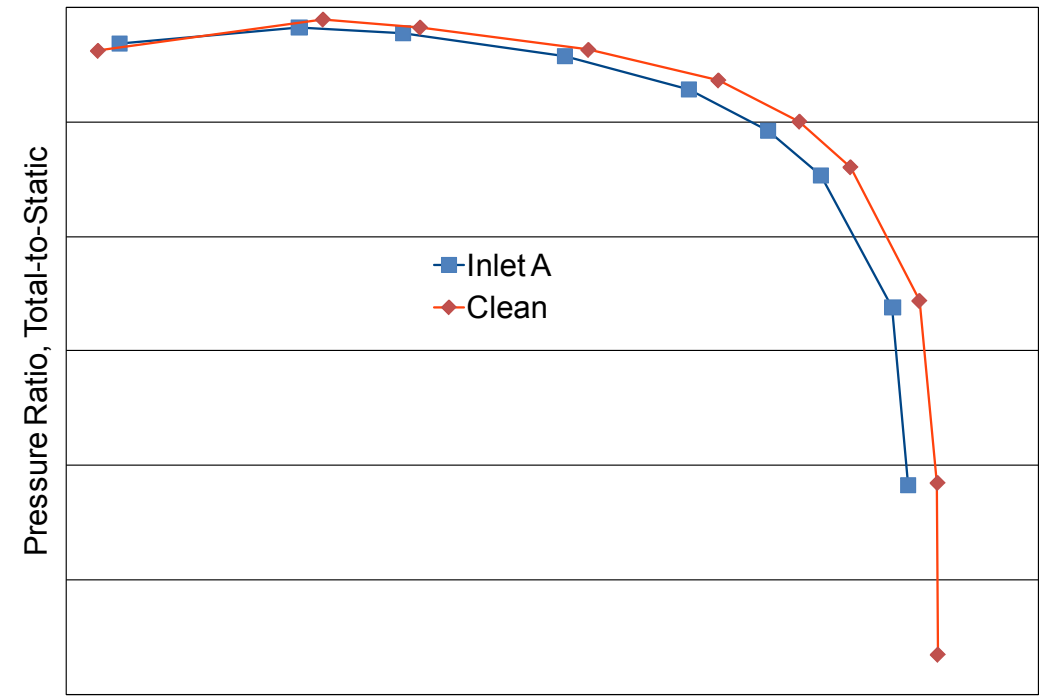

Corrected Mass Flow

Figure 11.-Pressure ratio $v$ corrected mass flow for clean and distorted inlets.

\section{Clean Inlet v Distorted Inlet: Aeroelastic Response}

The primary research interest here is the impact of a BLI inlet's distorted inflow on aeroelastic response of a fan. The subject test article has been shown (computationally and experimentally) to be aeromechanically stable near peak-efficiency for all blade-disk modes of interest with a clean inlet. However, experiment reveals aeromechanical instability as the machine approaches stall with a clean inlet. Previous TURBO analysis (single passage, relatively coarse grid, constant exit static pressure profile; not shown here) reveals a minimum of aeromechanical stability for the same mode and flow condition which had been observed as unstable in the physical experiment. 


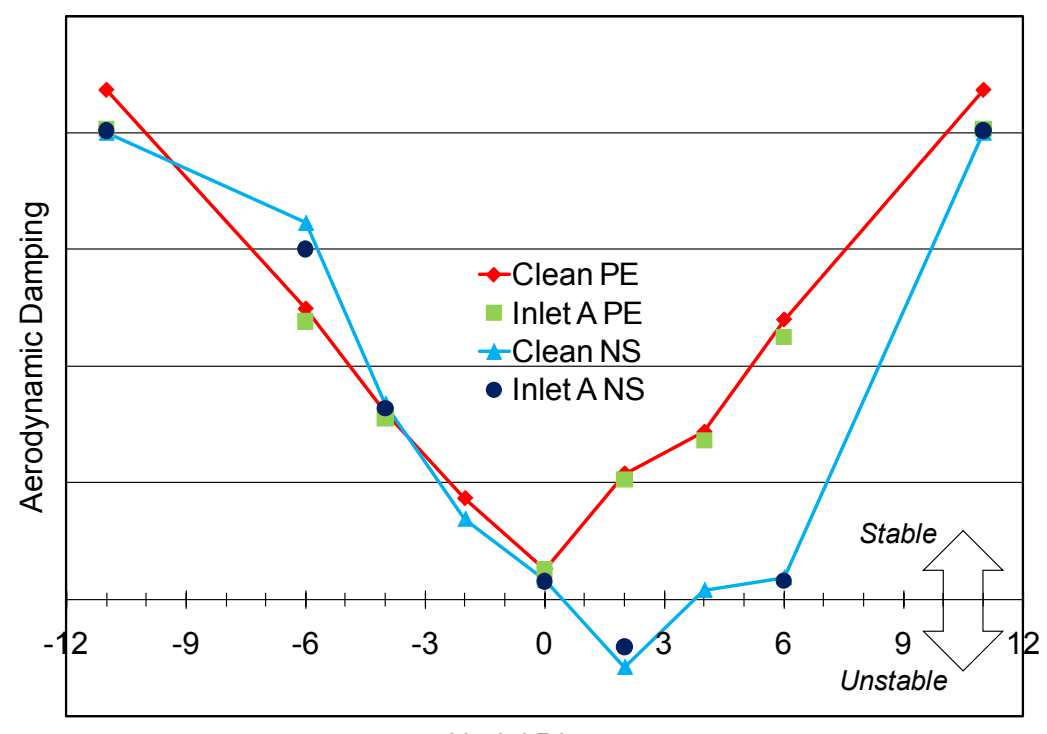

Nodal Diameter

Figure 12.-Aeroelastic sweeps for clean inlet and Inlet A, peak-efficiency and near-stall. Refined grid, full-annulus, throttle exit boundary condition.

Figure 12 plots the aeroelastic sweeps (full annulus, refined grid, throttle exit) for a first flexural mode about the nodal diameters of interest for both clean and distorted inlets at both peak-efficiency and near-stall flow conditions. The expanded (full annulus), refined grid with the throttle exit indeed shows the two nodal diameter forward traveling wave mode to be unstable, rather than minimally stable, with clean inlet flow at the near-stall condition. For both peak-efficiency and near-stall flow conditions, the aeroelastic stability for all nodal diameter (ND) wave modes is minimally changed when viewing the distorted inlet flows from an annular-averaged perspective. The Inlet A near-stall simulation of the 2NDB wave and the 4NDF wave modes did not satisfactorily converge in the time frame of this paper.

All aerodynamic damping quantities in Figure 12 represent annular averages of the twenty-two blades about the annulus. Observing that the magnitudes and general shapes of the aeroelastic sweeps are similar among all conditions (peak-efficiency and near-stall, clean inlet and Inlet A), the premise of averaging about the annulus seems reasonable, but closer inspection of the data, temporally and spatially, is quite revealing. In Figure 13, the fan has a consistent aeroelastic response to clean inlet flow near stall. The aerodynamic work of both the 2NDF and 11ND modes oscillates with small amplitude about the annulus, but it is clearly evident that the 11ND mode is stable while the 2NDF mode is unstable as is shown in Figure 12. Figure 14 plots the convergence of the annular-averaged aerodynamic work per cycle for the $11 \mathrm{ND}$ and 2NDF modes behind clean and distorted inlets; all converge nicely in their aeroelastic responses, irrespective of clean or distorted inlet condition, though the 2NDF modes are slightly unstable while the 11ND modes are solidly stable.

Figures 15 and 16 focus exclusively on the distorted inlet condition. Figure 15 shows the $180^{\circ}$ phaseshift in vibratory motion between neighboring blades for the 11ND mode, while Figure 16 clearly shows the in-phase vibratory motion of blades spatially separated by $180^{\circ}$ about the annulus for the 2NDF mode. In both figures, the aerodynamic work is plotted at the angular position of the blade at the completion of the vibratory cycle. The angular positions of the annulus' highest and lowest total pressures are annotated along with the direction of blade rotation to clarify the range of pressures through which the blade swept in the course of the single respective vibratory cycle. In Figure 15, the minimally-oscillating clean-inlet aerodynamic work is plotted; it is readily apparent that the annular-averaged aerodynamic work differs little between distorted inlet and clean inlet; the clean inlet is solidly stable. The borderline-instability of the $2 \mathrm{NDF}$ mode is demonstrated in Figure 16 by the slightly-positive clean-inlet aerodynamic work which 
again coincides with the mean of the distorted inlet's aerodynamic work variation about the annulus. In addition to its loss of global stability, the 2NDF mode also features a much greater band of oscillation (variation by angular position) - about 60 times the magnitude of its mean - in its aeroelastic response than the 11ND mode, which oscillates with a bandwidth of 10 times its mean.

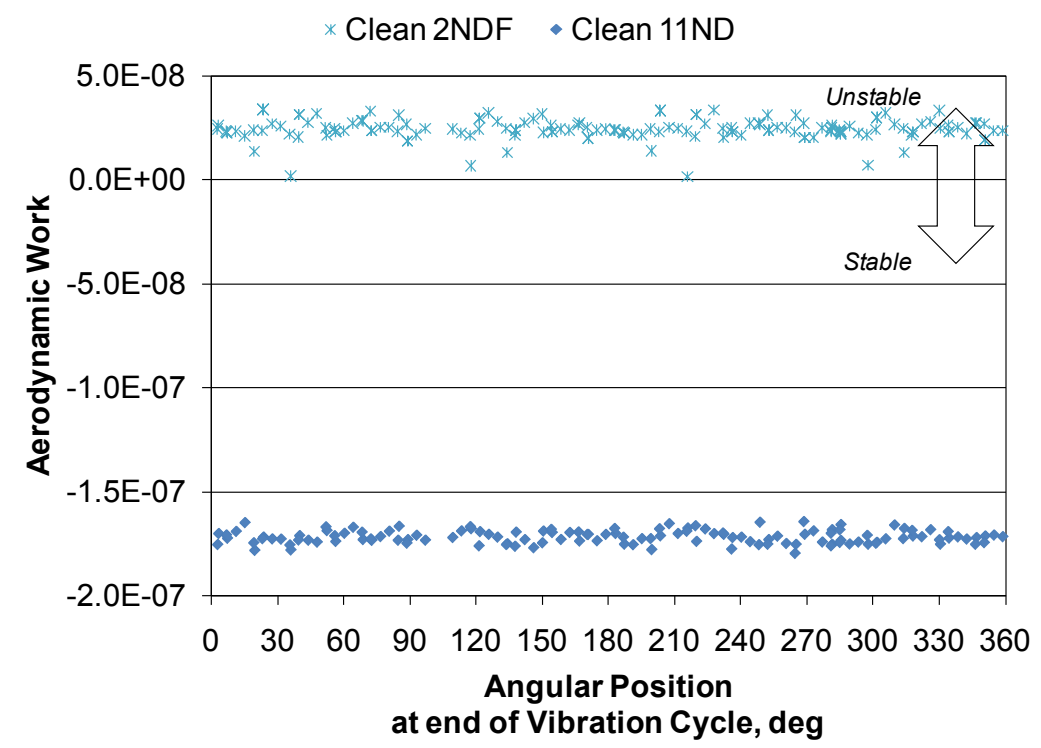

Figure 13.-Aerodynamic work $v$ angular position, near-stall, 11ND and 2NDF, clean inlet, all blades.

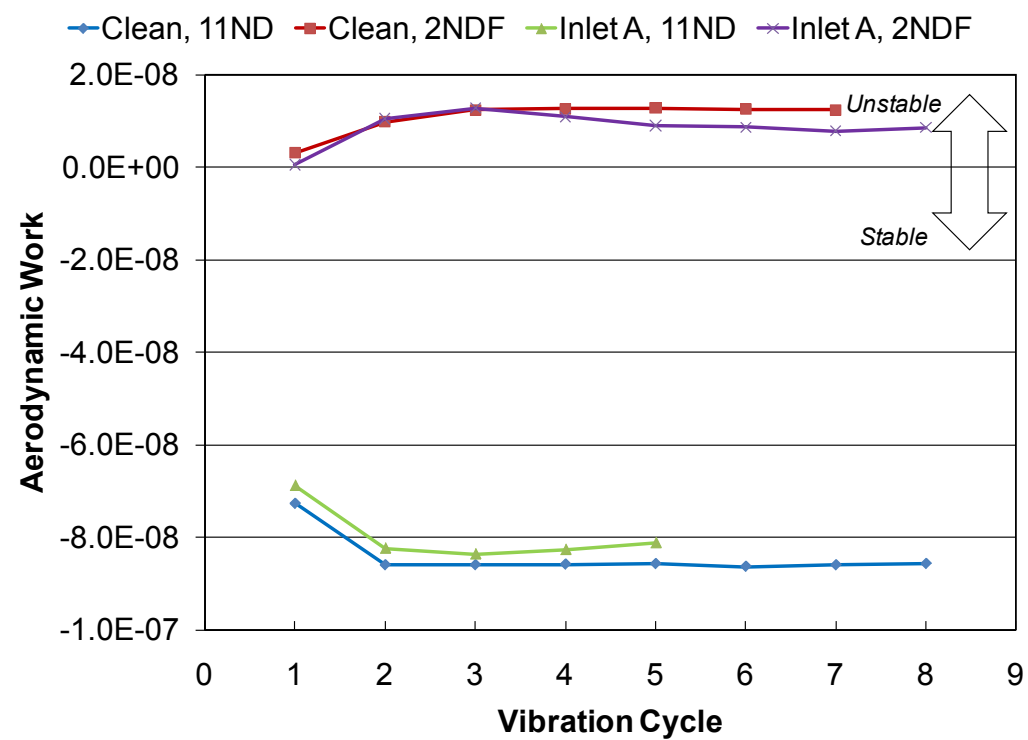

Figure 14.-Annular-averaged aerodynamic work v vibration cycle, nearstall. 


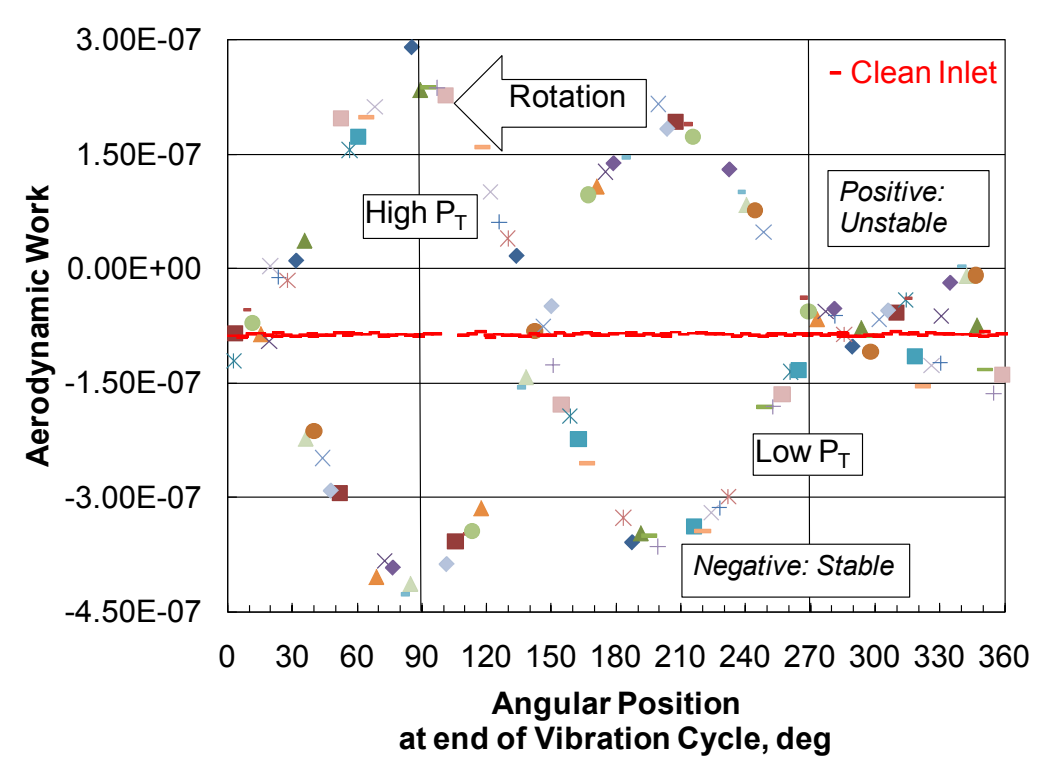

Figure 15.-Aerodynamic work v angular position, near-stall, 11ND, Inlet A, all blades.

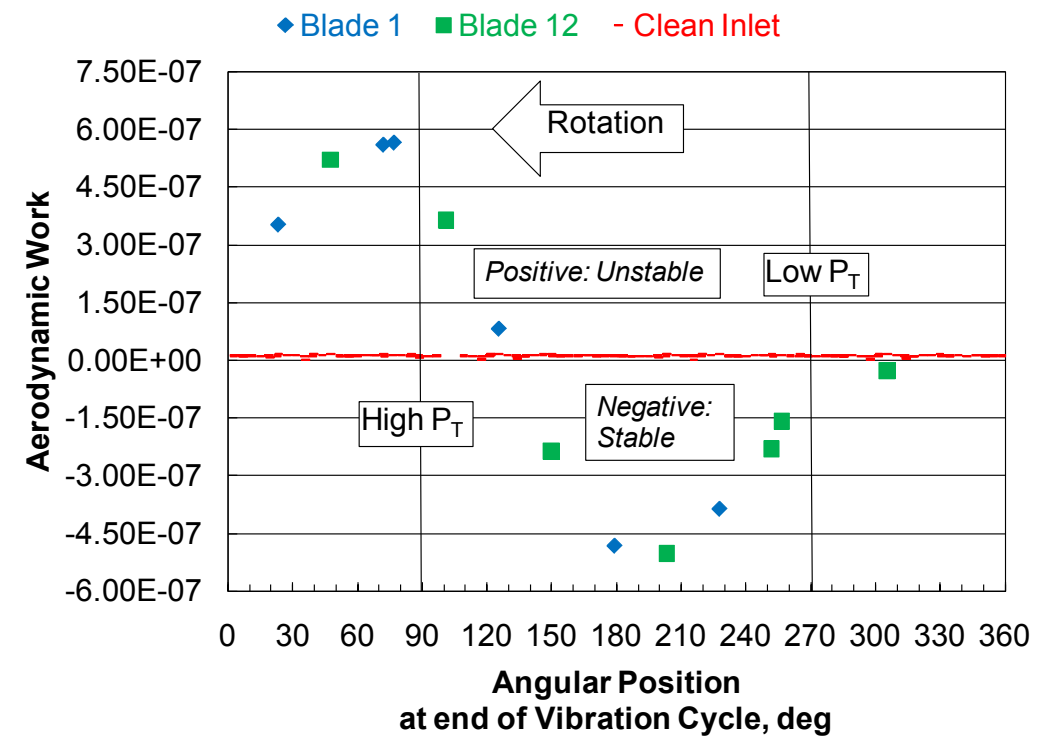

Figure 16.-Aerodynamic work $v$ angular position, near-stall, 2NDF, Inlet A, blades 1 and 12 .

\section{Conclusions and Recommendations}

An established CFD code, validated in the analysis of aerothermodynamic performance, fluid dynamics, and aeroelastics, has been modified and applied in a preliminary study of the effects of inlet distortion on aeroelastic stability of a high-speed forward-swept fan. Care was taken throughout the modifications of the code to ensure that numerical accuracy of the code was maintained. In developing the CFD representation of the fan, care was taken to ensure adequate gridding of the domain was prescribed for reliable solutions and that the simulations were manageable within available computational resources. The existing axisymmetric "total condition preserved" inlet boundary condition has been modified to handle circumferential nonuniformity. 
Application of the throttle exit boundary condition, allowing the exit flow to attain equilibrium without artificial constraint, has shown that inlet distortions do not fully attenuate upon passage through single rotor. The throttle boundary condition effectively emulated other static pressure exit boundary conditions in terms of global aerothermodynamic performance data for the given grid. It was observed when applying an inlet distortion of the nature of Inlet A to this research fan that distorted inlet aerothermodynamic performance was very similar to clean inlet performance when plotted on a corrected flow basis.

When examining aeroelastic behavior, the clean inlet solutions yield much cleaner, consistent solutions. The distorted inlet aeroelastic simulations introduce great oscillation to solidly stable flow conditions like the 11ND near-stall, Inlet A simulation; the aeroelastic response quantities oscillate much more greatly for the 2NDF near-stall Inlet A simulation. While the initial investigation into the effects of inlet distortion on aerodynamic damping suggest that the aeroelastic stability of the fan is minimally impacted by the inlet distortion, the magnitudes of the oscillations within the distorted flow simulations encourage further investigation into the details of the flow field. Much detailed numerical data has been produced and archived through the course of this study, and there is much left to investigate. It will be of great interest to interrogate the data in an unsteady manner. Each blade's aeroelastic response may be traced through the blade's temporal and spatial progression; some preliminary data has been presented here. In-depth study of this data may provide insight as to the dominant/critical issues of inlet distortion which have great adverse impact on aeromechanical stability and which factors/conditions present minimal adverse impact on aeromechanical stability.

\section{References}

1. Liebeck, R., "Design of the Blended-Wing-Body Subsonic Transport," AIAA Journal of Aircraft, Vol. 41, No. 1, pp. 10-25, 2004.

2. Smith, Leroy H., Jr., "Wake Ingestion Propulsion Benefit," AIAA Journal of Propulsion and Power, Vol. 9, No. 1, pp. 74-82, 1993.

3. Plas, A., Crichton, D., Sargeant, M., Hynes, T., Greitzer, E., Hall, C., and Madani, V., "Performance of a Boundary Layer Ingesting (BLI) Propulsion System," AIAA-2007-0450, Jan. 2007.

4. Kenyon, James A., Rabe, Douglas C., and Fleeter, Sanford, "Aerodynamic Effects on Vibratory Stress Variations," AIAA Journal of Propulsion and Power, Vol. 15, No. 5, Sep.-Oct. 1999, pp. 675-680.

5. Hah, Chunill, Rabe, Douglas C., Sullivan, Thomas J., and Wadia, Aspi R., "Effects of Inlet Distortion on the Flow Field in a Transonic Compressor Rotor," ASME Paper 96-GT-547, Jun. 1996.

6. Hirai, K.; Kodama, H., Nozaki, O., Kikuchi, K., Tamura, A., and Matsuo, Y, "Unsteady ThreeDimensional Analysis of Inlet Distortion in Turbomachinery,” AIAA-1997-2735, Jul. 1997.

7. Charalambous, Nikolaos, Ghisu, Tiziano, Iurisci, Giuseppe, Pachidis, Vassilios, and Pilidis, Pericles, "Axial Compressor Response to Inlet Flow Distortions by a CFD Analysis," ASME Paper GT200453846, Jun. 2004.

8. Yao, Jixian, Gorrell, Steven, and Wadia, Aspi, "A Time-Accurate CFD Analysis of Inlet Distortion Induced Swirl in Multistage Fans," AIAA-2007-5059, Jul. 2007.

9. Gorrell, Steven, Yao, Jixian, and Wadia, Aspi, "High Fidelity URANS Analysis of Swirl Generation and Fan Response to Inlet Distortion," AIAA-2008-4985, Jul. 2008.

10. Bréard, C., Vahdati, M., Sayma, A. I. and Imregun, M., "An Integrated Time-Domain Aeroelasticity Model for the Prediction of Fan Forced Response due to Inlet Distortion," ASME Journal of Engineering for Gas Turbines and Power, Vol. 124, No. 1, Jan. 2002, pp. 196-208.

11. Zemp, Armin, Kammerer, Albert, and Abhari, Reza S., "Unsteady CFD Investigation on Inlet Distortion in a Centrifugal Compressor," ASME Paper GT2008-50744, Jun. 2008.

12. Zhu, J. and Shih, T.H., "CMOTT Turbulence Model for NPARC," CR-204143, National Aeronautics and Space Administration, Aug. 1997. 
13. Chen, J.P. and Barter, J., "Comparison of Time-Accurate Calculations for the Unsteady Interaction in Turbomachinery Stage,” AIAA-1998-3292, Jul. 1998.

14. Chen, J.-P., and Whitfield, D.L., "Navier-Stokes Calculations for the Unsteady Flowfield of Turbomachinery," AIAA-1990-0676, Jan. 1990.

15. Chen, J.-P. and Briley, W.R., "A Parallel Flow Solver for Unsteady Multiple Blade Row Turbomachinery Simulations," ASME Paper GT2001-0348, Jun. 2001.

16. Srivastava, R., Bakhle, M.A., and Keith, T.G., Jr., "Numerical Simulation of Aerodynamic Damping for Flutter Analysis of Turbomachinery Blade Rows," AIAA Journal of Propulsion and Power, Vol. 19, No. 2, March 2003.

17. Srivastava, R., Bakhle, M.A., Keith, T.G., Jr., and Stefko, G.L., "Flutter Analysis of a Transonic Fan," ASME Paper GT-2002-30319, Jun. 2002.

18. Bakhle, M. A., Liu, Jong S., Panovsky, Josef, Keith, Theo G. Jr., and Mehmed, Oral, "Calculation and Correlation of the Unsteady Flowfield in a High Pressure Turbine," ASME Paper GT-200230322, Jun. 2002.

19. Panovsky, Josef, James, Darrell K., and Hassan, Khaled K., "An Assessment of Fan Flutter Using TURBO," $5^{\text {th }}$ National Turbine Engine High Cycle Fatigue Conference, published by Universal Technology Corporation, Dayton, OH, Apr. 2000.

20. Panovsky, J., Liu, J.S. and Bakhle, M.A., "Comparisons of Experimental and Computational Forced Response in a High Pressure Turbine," Proceedings of the 7th National Turbine High Cycle Fatigue Conference, published by Universal Technology Corporation, Dayton, OH, Apr. 2002.

21. Kielb, Robert E., Barter, John W., Thomas, Jeffrey P., and Hall, Kenneth C., "Blade Excitation by Aerodynamic Instabilities," ASME Paper GT2003-38634, Jun. 2003.

22. Sanders, A.J., Hassan, K.K. and Rabe, D.C., "Experimental and Numerical Study of Stall Flutter in a Transonic Low-Aspect Ratio Fan Blisk," ASME Journal of Turbomachinery, Vol. 126, No. 1, pp. 166-174.

23. Sanders, A.J., "Stall Flutter Assessment of and Advanced Design Transonic Fan Using TURBO-AE," Proceedings of the 6th National Turbine High Cycle Fatigue Conference, published by Universal Technology Corporation, Dayton, OH, Apr. 2001.

24. Sanders, A.J., "Nonsynchronous Vibration (NSV) due to a Flow-Induced Aerodynamic Instability in a Composite Fan Stator," ASME Journal of Turbomachinery, Vol. 127, No. 2, pp. 412-421.

25. Chen, Jen-Ping, Hathaway, Michael D., and Herrick, Gregory P., "Prestall Behavior of a Transonic Axial Compressor Stage via Time-Accurate Numerical Simulation," ASME Journal of Turbomachinery, Vol. 130, No. 4, Oct. 2008, pp. 041014.

26. Berrier, Bobby L, Carter, Melissa B., and Allan, Brian G., "High Reynolds Number Investigation of a Flush-Mounted, S-Duct Inlet with Large Amounts of Boundary Layer Ingestion," NASA/TP-2005213766, Sep. 2005. 


\begin{tabular}{|c|c|c|}
\hline \multicolumn{2}{|c|}{ REPORT DOCUMENTATION PAGE } & $\begin{array}{l}\text { Form Approved } \\
\text { OMB No. 0704-0188 }\end{array}$ \\
\hline \multicolumn{3}{|c|}{$\begin{array}{l}\text { The public reporting burden for this collection of information is estimated to average } 1 \text { hour per response, including the time for reviewing instructions, searching existing data sources, gathering and maintaining the } \\
\text { data needed, and completing and reviewing the collection of finformation. Send comments regarding this burden estimate or any other aspect of this collection of information, including suggestions for reducing this } \\
\text { burden, to Department of Defense, Washington Headquarters Services, Directorate for Information Operations and Reports (0704-0188), 1215 Jefferson Davis Highway, Suite } 1204 \text {, Arlington, VA } 222202-4302 \text {. } \\
\text { Respondents should be aware that notwithstanding any other provision of law, no person shall be subject to any penalty for failing to comply with a collection of information if it does not display a currently valid OMB } \\
\text { control number. } \\
\text { PLEASE DO NOT RETURN YOUR FORM TO THE ABOVE ADDRESS. }\end{array}$} \\
\hline $\begin{array}{l}\text { 1. REPORT DATE (DD-MM-YYYY) } \\
01-01-2011\end{array}$ & $\begin{array}{l}\text { 2. REPORT TYPE } \\
\text { Technical Memorandum }\end{array}$ & 3. DATES COVERED (From - To) \\
\hline \multirow{3}{*}{\multicolumn{2}{|c|}{$\begin{array}{l}\text { 4. TITLE AND SUBTITLE } \\
\text { Effects of Inlet Distortion on Aeromechanical Stability of a Forwarc }\end{array}$}} & 5a. CONTRACT NUMBER \\
\hline & & 5b. GRANT NUMBER \\
\hline & & 5c. PROGRAM ELEMENT NUMBER \\
\hline \multirow{3}{*}{\multicolumn{2}{|c|}{$\begin{array}{l}\text { 6. AUTHOR(S) } \\
\text { Herrick, Gregory, P. }\end{array}$}} & 5d. PROJECT NUMBER \\
\hline & & 5e. TASK NUMBER \\
\hline & & $\begin{array}{l}\text { 5f. WORK UNIT NUMBER } \\
\text { WBS 561581.02.08.03.21.18.01 }\end{array}$ \\
\hline \multicolumn{2}{|c|}{$\begin{array}{l}\text { 7. PERFORMING ORGANIZATION NAME(S) AND ADDRESS(ES) } \\
\text { National Aeronautics and Space Administration } \\
\text { John H. Glenn Research Center at Lewis Field } \\
\text { Cleveland, Ohio 44135-3191 }\end{array}$} & $\begin{array}{l}\text { 8. PERFORMING ORGANIZATION } \\
\text { REPORT NUMBER } \\
\text { E-17564 }\end{array}$ \\
\hline \multirow{2}{*}{\multicolumn{2}{|c|}{$\begin{array}{l}\text { 9. SPONSORING/MONITORING AGENCY NAME(S) AND ADDRESS(ES) } \\
\text { National Aeronautics and Space Administration } \\
\text { Washington, DC 20546-0001 }\end{array}$}} & $\begin{array}{l}\text { 10. SPONSORING/MONITOR'S } \\
\text { ACRONYM(S) } \\
\text { NASA }\end{array}$ \\
\hline & & $\begin{array}{l}\text { 11. SPONSORING/MONITORING } \\
\text { REPORT NUMBER } \\
\text { NASA/TM-2011-216959 }\end{array}$ \\
\hline \multicolumn{3}{|c|}{$\begin{array}{l}\text { 12. DISTRIBUTION/AVAILABILITY STATEMENT } \\
\text { Unclassified-Unlimited } \\
\text { Subject Categories: } 01,07,34,39,61 \text {, and } 64 \\
\text { Available electronically at http://gltrs.grc.nasa.gov } \\
\text { This publication is available from the NASA Center for AeroSpace Information, 443-757-5802 }\end{array}$} \\
\hline
\end{tabular}

\section{SUPPLEMENTARY NOTES}

\section{ABSTRACT}

Concerns regarding noise, propulsive efficiency, and fuel burn are inspiring aircraft designs wherein the propulsive turbomachines are partially (or fully) embedded within the airframe; such designs present serious concerns with regard to aerodynamic and aeromechanic performance of the compression system in response to inlet distortion. Separately, a forward-swept high-speed fan was developed to address noise concerns of modern podded turbofans; however this fan encounters aeroelastic instability (flutter) as it approaches stall. A threedimensional, unsteady, Navier-Stokes computational fluid dynamics code is applied to analyze and corroborate fan performance with clean inlet flow. This code, already validated in its application to assess aerodynamic damping of vibrating blades at various flow conditions, is modified and then applied in a computational study to preliminarily assess the effects of inlet distortion on aeroelastic stability of the fan. Computational engineering application and implementation issues are discussed, followed by an investigation into the aeroelastic behavior of the fan with clean and distorted inlets.

\section{SUBJECT TERMS}

Aeroelasticity; Turbomachinery; Turbofan; Flutter; Computational fluid dynamics; Inlet distortion; Vibration

\begin{tabular}{|c|c|c|c|c|c|}
\hline \multicolumn{3}{|c|}{ 16. SECURITY CLASSIFICATION OF: } & \multirow{2}{*}{$\begin{array}{l}\text { 17. LIMITATION OF } \\
\text { ABSTRACT } \\
\text { UU }\end{array}$} & \multirow{2}{*}{$\begin{array}{l}\text { 18. NUMBER } \\
\text { OF } \\
\text { PAGES } \\
20\end{array}$} & \multirow{2}{*}{$\begin{array}{l}\text { 19a. NAME OF RESPONSIBLE PERSON } \\
\text { STI Help Desk (email:help@sti.nasa.gov) } \\
\text { 19b. TELEPHONE NUMBER (include area code) } \\
\text { 443-757-5802 }\end{array}$} \\
\hline $\begin{array}{l}\text { a. REPORT } \\
U\end{array}$ & $\begin{array}{l}\text { b. ABSTRACT } \\
U\end{array}$ & $\begin{array}{l}\text { c. THIS } \\
\text { PAGE } \\
\text { U }\end{array}$ & & & \\
\hline
\end{tabular}



